\title{
Meniscal Preservation is More Likely When Performed with Acute Anterior Cruciate Ligament Repair Rather Than with Anterior Cruciate Ligament Reconstruction
}

\author{
WILLIAM Thomas WILSON ( $\square$ william.wilson@glasgow.ac.uk) \\ University of Strathclyde https://orcid.org/0000-0001-9025-081X \\ Graeme Philip Hopper \\ NHS Greater Glasgow and Clyde \\ Chris Hamilton \\ NHS Greater Glasgow and Clyde \\ Lucas O'Donnell \\ NHS Greater Glasgow and Clyde \\ Mark J.G. Blyth \\ NHS Greater Glasgow and Clyde \\ Gordon M MacKay \\ Rosshall Hospital, Glasgow
}

\section{Research Article}

Keywords: Meniscus, repair, preservation, acute, ACL

Posted Date: January 28th, 2022

DOI: https://doi.org/10.21203/rs.3.rs-1280111/v1

License: (c) (i) This work is licensed under a Creative Commons Attribution 4.0 International License.

Read Full License

Version of Record: A version of this preprint was published at Surgical Technology Online on February 2nd, 2022. See the published version at https://doi.org/10.52198/22.STI.40.0S1574. 


\section{Abstract}

\section{Background}

Rupture of the anterior cruciate ligament $(\mathrm{ACL})$ often occurs in conjunction with meniscal tears. In this study we investigate the rates and outcomes of meniscal repair surgery performed with ACL reconstruction compared with acute ACL repair surgery.

\section{Methods}

Data was collected for all patients undergoing surgery for ACL ruptures between 2012 and 2018, including ACL reconstruction with hamstring autograft and primary ACL repair augmented with suture tape. Patients undergoing multiligament surgery was excluded. Meniscal injury was evaluated intraoperatively and the treatment determined by type of tear, reducibility, and quality of meniscal tissue. If possible, tears were repaired using all-inside anchors and all others were resected.

\section{Results}

There were $272 \mathrm{ACL}$ reconstructions and $134 \mathrm{ACL}$ repairs, mean age was $28( \pm 9)$ and $35( \pm 14)$ years respectively $(p<0.01)$. The mean Tegner activity score was 6.6 in both groups. The mean interval from injury to surgery was longer in the reconstruction group ( 26.2 v 1.3 months, $p<0.01) .55 \%$ of reconstructions and $43 \%$ of $A C L$ repairs required meniscal surgery at the time of their ACL procedure. In the reconstruction group 123 (70\%) were meniscectomies and $53(30 \%)$ were meniscal repairs, compared to $31(50 \%)$ of each in the ACL repair group. Meniscal repair was more likely to be possible when carried out as part of acute $A C L$ repair surgery, $\chi 2(1, n=238)=7.94, p<0.01$. The success rate of meniscal repair was $97 \%$ in both groups.

\section{Conclusions}

The rate of meniscal repair is $67 \%$ higher when performed early with ACL repair. When ACL reconstruction is performed, meniscal resection was more likely. Rates of post-traumatic osteoarthritis are high after ACL reconstruction when performed with meniscal resection. Furthermore, the success rate of meniscal repair in conjunction with ACL surgery is high (97\%). Therefore, meniscal repair should be encouraged whenever possible to improve long term outcomes.

\section{Level of Evidence: III}

\section{Introduction}

Rupture of the anterior cruciate ligament (ACL) is a common injury associated with pivoting sports and often occurs in conjunction with meniscal tears [1,2]. It is well understood that an ACL injury is associated with a high chance of developing osteoarthritis in that knee, despite reconstruction [3-5]. 
Meniscal injuries occurring either at the time of the ACL injury or subsequently increase the risk of osteoarthritis [6-8].

The treatment of meniscal injury at ACL surgery varies [2]. Rates of meniscal resection remain high when carried out with ACL reconstruction, despite concerns regarding its contribution to the development of osteoarthritis prompting a move towards meniscal preservation $[9,10]$. Noyes and Barber Westin (11) performed a systematic review and identified that resection remains the most common treatment of meniscal injury in the ACL deficient knee undergoing reconstruction, occurring in $65 \%$ of knees with meniscal repair in only one third.

Pujol and Beaufils (12) demonstrated in a systematic review, outcomes in favour of leaving small lateral meniscal lesions untreated, rather than resection, during ACL reconstruction due to low failure rates. Whilst some authors have attempted to synthesise the literature regarding when to resect, repair or leave alone there remains no evidence-based consensus [13]. Despite that, improved understanding of the biomechanical function of the meniscus in conjunction with the wide availability of advanced arthroscopic repair techniques have made meniscal preservation more desirable and widely practised.

Outcomes of meniscal repair surgery performed at the same time as ACL reconstruction are superior to when performed in isolation $[14,15]$. Any evidence which exists regarding outcomes of meniscal surgery with ACL surgery relates to $A C L$ reconstruction. There is no literature regarding incidence of meniscal surgery and the outcomes associated with modern primary ACL repair techniques.

In this study we aimed to investigate the rates and outcomes of meniscal repair surgery performed with ACL reconstruction and compare with the rates when performed with acute ACL repair with internal brace surgery. We hypothesised that there would be no difference in rate of meniscal preservation surgery between $A C L$ reconstruction and ACL repair.

\section{Methods}

Data was collected for all patients undergoing surgery with our group for ACL rupture between June 2012 and September 2018 and split into two groups: those having ACL reconstruction with hamstring autograft and those having primary ACL repair augmented with suture tape. The suitability for primary ACL repair surgery was determined by the surgeon intra-operatively depending on location of the ACL tear and quality of residual ACL tissue. Those with multi-ligament injuries were excluded. Meniscal injury was evaluated intra-operatively and the treatment determined by the surgeon based upon location and size of tear, reducibility of the displaced fragment and quality of meniscal tissue. Meniscal tears which met the criteria were repaired using an all-inside technique with anchors and the others were treated with partial meniscectomy. The hardware used for meniscal repair was either FiberStitch ${ }^{\text {TM }}$ anchors (Arthrex, Naples, Florida, USA) or Fast-Fix ${ }^{\text {TM }}$ (Smith and Nephew, Watford, UK). Patients were followed up directly for 6 months postoperatively and at the time of the study, were contacted and case notes reviewed to identify any further surgery to the knee. Information recorded were basic demographics, mechanism of injury, 
Tegner activity score, interval between injury and surgery, the nature of any meniscal surgery performed and any further meniscal surgery.

Descriptive statistics were calculated to summarise the demographics and clinical characteristics and described with means and standard deviations for normally distributed data or median with ranges for non-normally distributed data. Normality was assessed using the Shapiro-Wilk test. Unpaired students ttests or Mann-Whitney $U$ tests were performed to compare variables between groups. Chi-squared tests used to identify differences in occurrence rates between groups and the significance level set a $p<0.05$. Correlations were investigated using Pearson or Spearman correlation coefficient as appropriate. All analyses were performed with SPSS, version 27 (IMB, Chicago, IL, USA). Ethical approval for the study was granted by the University of Strathclyde ethics committee (UEC19/24).

\section{Results}

A total of 410 patients were included, with 4 lost to follow up leaving $272(67 \%)$ who had ACL reconstruction and $134(33 \%)$ primary ACL repair with internal bracing. The mean age for the reconstruction group was $28( \pm 9)$ years and for repair was $35( \pm 14)$ years $(p<0.01)$ and there were a higher proportion of males in the reconstruction group ( $82 \%$ versus $56 \%, p<0.01)$. Pre-injury activity level was the same in both groups, median Tegner score 7 (range 1 - 10), and most injuries were sustained during sport with soccer, rugby and skiing contributing to approximately $70 \%$ overall. There was no difference in follow-up time, which was a mean of 5 years for both groups, with minimum follow-up period of 2 years postoperative. The median interval from injury to surgery was significantly longer in the reconstruction group (12 months $v 1$ month, $p<0.001$ ) (Figure 1).

In total, 208 patients $(51 \%)$ required meniscal surgery at the time of their ACL procedure, $55 \%$ of reconstructions and $43 \%$ of all ACL repairs. There was no difference between groups for which meniscus was injured (51\% lateral meniscus) with a total of 238 meniscal surgeries performed. Of these, in the reconstruction group $123(70 \%)$ were meniscectomies and $53(30 \%)$ were meniscal repairs compared to 31 (50\%) and 31 (50\%) respectively in the ACL repair group. (Figure 2) A chi-square test of independence was performed which demonstrated that meniscal repair was more likely to be possible when carried out as part of acute ACL repair surgery, $\chi^{2}(1, n=238)=7.94, p<0.01$. Figure 3 shows the breakdown of specific meniscal surgery for each group.

There was an inverse correlation between repairability of meniscus and time interval from injury to surgery $\left(r_{s}=-0.27, p<0.01\right)$. Considering all meniscal tears, those which were deemed to be repairable had a significantly shorter median interval from injury to surgery ( 5 months) than those which were irreparable (12 months) ( $p<0.001)$ (Figure 4). We grouped all patients, irrespective of ACL surgery type, by time intervals from injury to surgery (Figure 5 ). This shows a significant decrease in repairability rate of meniscal tears as the wait time increases from 0 to 3 months, to 4 to 6 months. After 6 months, the rate of meniscal repairability plateaus around $30 \%$. 
Patients undergoing meniscal repair rather than resection also tended to be younger, mean age 27 versus $32(p=0.003)$. For those tears requiring partial meniscectomy compared to those which did not, there was a statistically significant difference in the time interval to surgery for medial tears $(p<0.001)$ but not for lateral tears $(p=0.11)$.

The success rate of meniscal repair surgery was not different between ACL treatment group, $96.3 \%$ for reconstruction versus $96.7 \%$ for ACL repair, and not influenced by time interval.

\section{Discussion}

The main finding of this study was that the rate of meniscal repair surgery is $67 \%$ higher when the surgery is performed early in conjunction with ACL repair surgery compared to conventional ACL reconstruction. When $A C L$ reconstruction is performed in our group, meniscal resection is more likely.

It is well understood that following an ACL rupture, rates of early onset post-traumatic osteoarthritis are high, and not necessarily influenced by ACL reconstruction [9, 16-19]. Rates of osteoarthritis may actually be higher when ACL reconstruction performed, with or without meniscectomy $[5,16]$.

Furthermore, resection of meniscus is associated with a marked increase in the rate of development of osteoarthritis. Indeed, recent studies from registry data in the UK have demonstrated that young patients who have partial meniscectomy have a forty-fold increase in lifetime risk of requiring knee arthroplasty [9]. Therefore, retention of meniscal tissue by repair should be encouraged whenever possible. In fact, when carried out in conjunction with ACL surgery, the success rates of meniscal repair are known to be greater, as high as 94\% [15]. This finding was re-enforced with the findings of this study, which showed a success rate of $96 \%$ for meniscal repair in conjunction with ACL surgery.

The main difference between the ACL treatment groups was the time interval between injury and surgery and it is this factor that likely contributed to the difference in repairability of meniscus, as supported by the correlation found in this study. Over time, the torn meniscal tissue quality deteriorates and is more difficult to reduce, rendering it irreparable. For this reason, early intervention should be encouraged, but is often not possible due to health service waiting times, or the desire to try conservative rehabilitation prior to surgery. For ACL repair surgery to be possible it requires to be performed within approximately three months, but as soon as possible after the acute trauma to the knee has settled. In this study, for all patients, the rate of meniscal repair was significantly highest when ACL surgery was performed within three months of injury, while rates were lowest after a six month delay, plateauing from that point on. From this data, we suggest that for the sake of meniscal preservation, surgery should be performed within three months, but no later than six months post-injury.

Slauterbeck, Kousa (20) demonstrated an increase in meniscal and chondral injury frequency and severity with increasing time to surgery. Theoretically, ACL surgery could prevent these injuries by stabilising the knee and preventing unpredictable episodes of knee giving way which place the structures at risk. Several authors have made recommendations for the timing of ACL reconstruction to avoid 
further meniscal injuries, however they are contrasting; 3 months [20, 21], 6 months [22] and 1 year [23] have all been proposed. It is recognised that healthcare system constraints may be the limiting factor, despite an appreciation that delays may increase the likelihood of chondral or meniscal pathology [24].

A cross-sectional study by Tomihara et al. [25] set about identifying risk factors for irreparable meniscal injuries. Results showed a strong association between irreparable medial meniscal injuries and time from injury to ACL reconstruction surgery of more than 3 months. This finding was re-enforced by this study, which showed that the time to surgery was significantly longer in cases when irreparable medial meniscal tears were present.

In another study, de Roeck and Lang-Stevenson (26) found that over $10 \%$ of patients sustained meniscal tears during the time from diagnosis of $\mathrm{ACL}$ tear to time of reconstruction rather than at time of $\mathrm{ACL}$ injury. This is most likely because of the posterior horn of the medial meniscus having a significant contribution to stability of the ACL deficient knee $[27,28]$. Furthermore, Millett, Willis $(29)$ demonstrated a threefold increase in meniscal tears in chronic ACL injury cases of $36 \%$ at more than 6 weeks post-injury, compared to $11 \%$ in acute cases.

The main limitations of our study are that it was retrospective in its design and there was no randomisation into the two cohorts. Nonetheless, the findings of our study support early intervention for ACL surgery to prevent the development of irreparable meniscal tears, the resection of which is likely to markedly hinder long term outcome. These recommendations have previously been made in connection with early ACL reconstruction [30]. One concern often mentioned with regard to early intervention for ACL surgery is postoperative stiffness and arthrofibrosis, however the rate of post-operative stiffness in this study was low (1\%) and not different between treatment groups.

Overall, there remains a distinct lack of high-level evidence with regards to the long term protective role of meniscal repair at time of ACL surgery, in contrast to meniscectomy. The results of this study show that there is an opportunity to explore this avenue further and to boost rates of repairability of meniscal tears by intervening early, in this case with acute ACL repair. This is in addition to the potential benefits that primary ACL repair might have, with rendition of native tissue and proprioceptive fibres [31]. This has the potential to help prevent the challenging problem of post-traumatic osteoarthritis in patients with an ACL rupture and associated meniscal injury.

\section{Conclusion}

This study shows that the rate of meniscal repair as an alternative to meniscal resection can be increased by $67 \%$ when carried out acutely in conjunction with ACL repair surgery, in comparison to delayed ACL reconstruction. The key factor for meniscal preservation is the time interval from injury to surgery, which should ideally be within three months but no later than six months. Higher rates of meniscal retention as well as retained native ACL tissue could potentially help to reduce long term risk of osteoarthritis. 


\section{Declarations}

Ethical Approval: University of Strathclyde ethics committee (UEC19/24).

Consent to Participate: Obtained

Consent to Publish: Obtained

Author Contributions: WW \& GH conceptualised study, CH \& LO were involved in data extraction, WW performed data analysis and wrote the manuscript writing. MB, GH \& GM reviewed and edited manuscript.

Funding: No funding

Competing Interests: GM is a consultant for Arthrex. The remaining authors have no conflicts to declare.

Availability of data and materials: All available

\section{References}

1. Filbay SR, Grindem $\mathrm{H}$. Evidence-based recommendations for the management of anterior cruciate ligament (ACL) rupture. Best Pract Res Clin Rheumatol. 2019;33(1):33-47.

2. Hewett TE, Myer GD, Ford KR, Paterno MV, Quatman CE. Mechanisms, prediction, and prevention of ACL injuries: Cut risk with three sharpened and validated tools. J Orthop Res. 2016;34(11):1843-55.

3. Øiestad BE, Engebretsen L, Storheim K, Risberg MA. Winner of the 2008 Systematic Review Competition: Knee Osteoarthritis after Anterior Cruciate Ligament Injury. Am J Sports Med. 2009;37(7):1434-43.

4. Risberg MA, Oiestad BE, Gunderson R, Aune AK, Engebretsen L, Culvenor A, et al. Changes in Knee Osteoarthritis, Symptoms, and Function After Anterior Cruciate Ligament Reconstruction. Am J Sports Med. 2016;44(5):1215-24.

5. Group MK, Jones MH, Oak SR, Andrish JT, Brophy RH, Cox CL, et al. Predictors of Radiographic Osteoarthritis 2 to 3 Years After Anterior Cruciate Ligament Reconstruction: Data From the MOON Onsite Nested Cohort. Orthop J Sports Med. 2019;7(8):2325967119867085-

6. Øiestad BE, Holm I, Aune AK, Gunderson R, Myklebust G, Engebretsen L, et al. Knee Function and Prevalence of Knee Osteoarthritis after Anterior Cruciate Ligament Reconstruction. Am J Sports Med. 2010;38(11):2201-10.

7. van Meer BL, Meuffels DE, van Eijsden WA, Verhaar JAN, Bierma-Zeinstra SMA, Reijman M. Which determinants predict tibiofemoral and patellofemoral osteoarthritis after anterior cruciate ligament injury? A systematic review. Br J Sports Med. 2015;49(15):975-83.

8. van Meer BL, Oei EHG, Meuffels DE, van Arkel ERA, Verhaar JAN, Bierma-Zeinstra SMA, et al. Degenerative Changes in the Knee 2 Years After Anterior Cruciate Ligament Rupture and Related Risk 
Factors. Am J Sports Med. 2016;44(6):1524-33.

9. Abram TBJ.J.G.F., Judge A, Beard DJ, Carr AJ, Price AJ. Long-term rates of knee arthroplasty in a cohort of 834393 patients with a history of arthroscopic partial meniscectomy. Bone Joint J. 2019;101-B(9):1071-80.

10. Abram SGF, Price AJ, Judge A, Beard DJ. Anterior cruciate ligament (ACL) reconstruction and meniscal repair rates have both increased in the past 20 years in England: hospital statistics from 1997 to 2017. Br J Sports Med. 2020;54(5):286-91.

11. Noyes FR, Barber Westin SD. Anterior Cruciate Ligament Injury Prevention Training in Female Athletes. Sports Health. 2011;4(1):36-46.

12. Pujol N, Beaufils P. During ACL reconstruction, small asymptomatic meniscal lesions can be left untreated: a systematic review. JISAKOS. 2016;1(3):135-40.

13. Pujol N, Beaufils P. Healing results of meniscal tears left in situ during anterior cruciate ligament reconstruction: a review of clinical studies. Knee Surg Sports Traumatol Arthrosc. 2009;17(4):396401.

14. Warren RF. (1990) Meniscectomy and repair in the anterior cruciate ligament-deficient patient. Clin Orthop Relat Res, (252):55-63.

15. Konan S, Haddad FS. Outcomes of meniscal preservation using all-inside meniscus repair devices. Clin Orthop Relat Res. 2010;468(5):1209-13.

16. Friel NA, Chu CR. The Role of ACL Injury in the Development of Posttraumatic Knee Osteoarthritis. Clin Sports Med. 2013;32(1):1-12.

17. Lohmander LS, Englund PM, Dahl LL, Roos EM. The Long-term Consequence of Anterior Cruciate Ligament and Meniscus Injuries. Am J Sports Med. 2007;35(10):1756-69.

18. Lohmander LS, Östenberg A, Englund M, Roos H. High prevalence of knee osteoarthritis, pain, and functional limitations in female soccer players twelve years after anterior cruciate ligament injury. Arthritis Rheum. 2004;50(10):3145-52.

19. Wang L-J, Zeng N, Yan Z-P, Li J-T, Ni G-X. (2020) Post-traumatic osteoarthritis following ACL injury. Arthritis Res Ther, 22(1).

20. Slauterbeck JR, Kousa P, Clifton BC, Naud S, Tourville TW, Johnson RJ, et al. Geographic Mapping of Meniscus and Cartilage Lesions Associated with Anterior Cruciate Ligament Injuries. J Bone Joint Surg Am. 2009;91(9):2094-103.

21. Papastergiou SG, Koukoulias NE, Mikalef P, Ziogas E, Voulgaropoulos H. Meniscal tears in the ACLdeficient knee: correlation between meniscal tears and the timing of ACL reconstruction. Knee Surg Sports Traumatol Arthrosc. 2007;15(12):1438-44.

22. O'Connor DP, Laughlin MS, Woods GW. Factors related to additional knee injuries after anterior cruciate ligament injury. Arthroscopy: The Journal of Arthroscopic Related Surgery. 2005;21(4):4318. 
23. Tandogan RN, Taşer Ö, Kayaalp A, Taşkıran E, Pınar H, Alparslan B, et al. Analysis of meniscal and chondral lesions accompanying anterior cruciate ligament tears: relationship with age, time from injury, and level of sport. Knee Surg Sports Traumatol Arthrosc. 2003;12(4):262-70.

24. Razi M, Salehi S, Dadgostar H, Cherati AS, Moghaddam AB, Tabatabaiand SM, et al. Timing of Anterior Cruciate Ligament Reconstruction and Incidence of Meniscal and Chondral Injury within the Knee. Int J Prev Med. 2013;4(Suppl 1):98-103.

25. Tomihara T, Hashimoto Y, Takahashi S, Taniuchi M, Takigami J, Okazaki S, et al. Risk Factors Related to the Presence of Meniscal Injury and Irreparable Meniscal Tear at Primary Anterior Cruciate Ligament Reconstruction. Orthop J Sports Med. 2021;9(3):232596712198903.

26. de Roeck NJ, Lang-Stevenson A. Meniscal tears sustained awaiting anterior cruciate ligament reconstruction. Injury. 2003;34(5):343-5.

27. Ahn JH, Bae TS, Kang K-S, Kang SY, Lee SH. Longitudinal Tear of the Medial Meniscus Posterior Horn in the Anterior Cruciate Ligament-Deficient Knee Significantly Influences Anterior Stability. Am J Sports Med. 2011;39(10):2187-93.

28. Markolf KL, Jackson SR, McAllister DR. Force Measurements in the Medial Meniscus Posterior Horn Attachment. Am J Sports Med. 2011;40(2):332-8.

29. Millett PJ, Willis AA, Warren RF. Associated injuries in pediatric and adolescent anterior cruciate ligament tears: does a delay in treatment increase the risk of meniscal tear? Arthroscopy. 2002;18(9):955-9.

30. Hagino T, Ochiai S, Senga S, Yamashita T, Wako M, Ando T, et al. Meniscal tears associated with anterior cruciate ligament injury. Arch Orthop Trauma Surg. 2015;135(12):1701-6.

31. Wilson WT, Hopper GP, Byrne PA, MacKay GM. Anterior Cruciate Ligament Repair with Internal Brace Ligament Augmentation. Surg Technol Int. 2016;29:273-8.

\section{Figures}




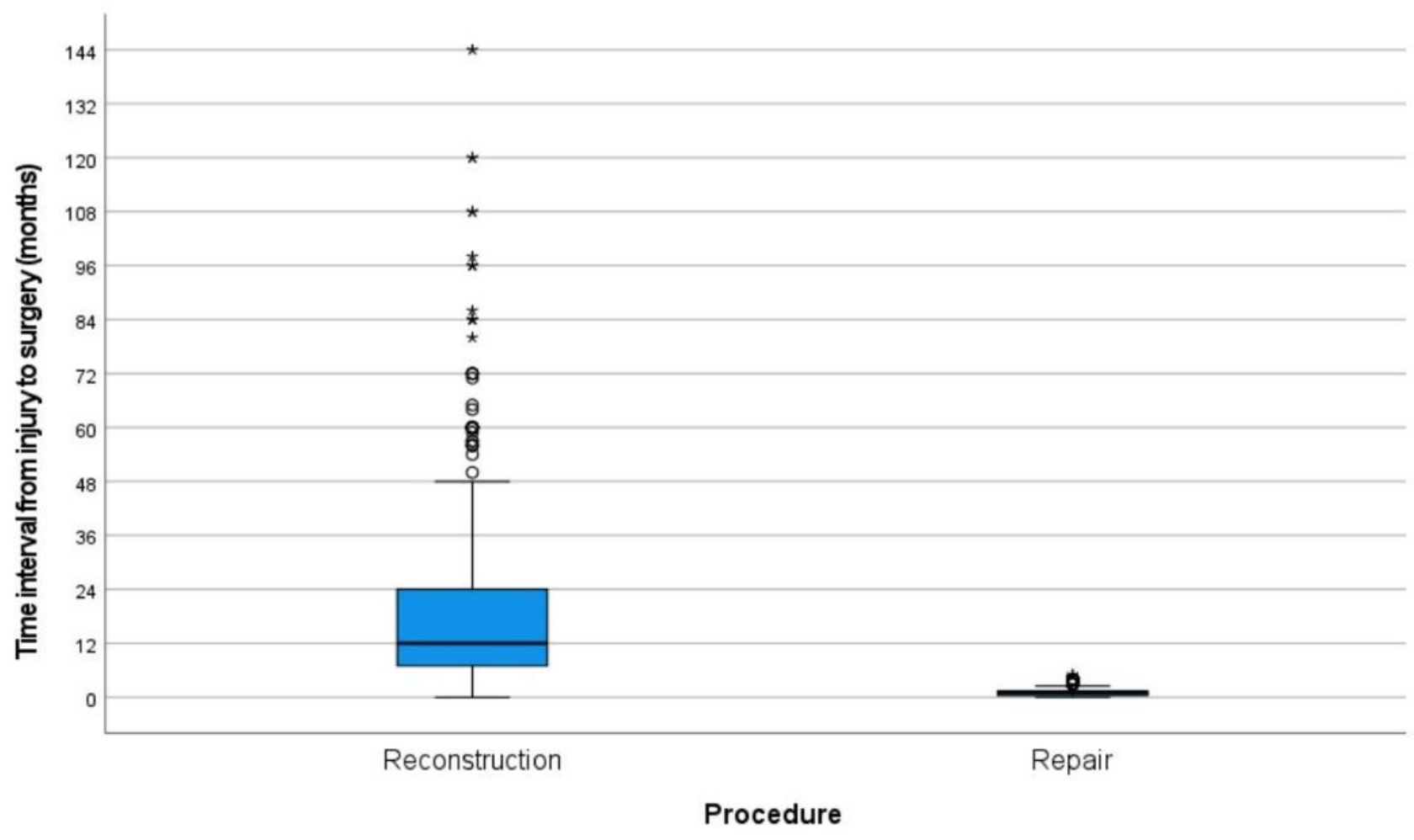

Figure 1

Boxplot demonstrating the time interval from injury to surgery for each treatment group 


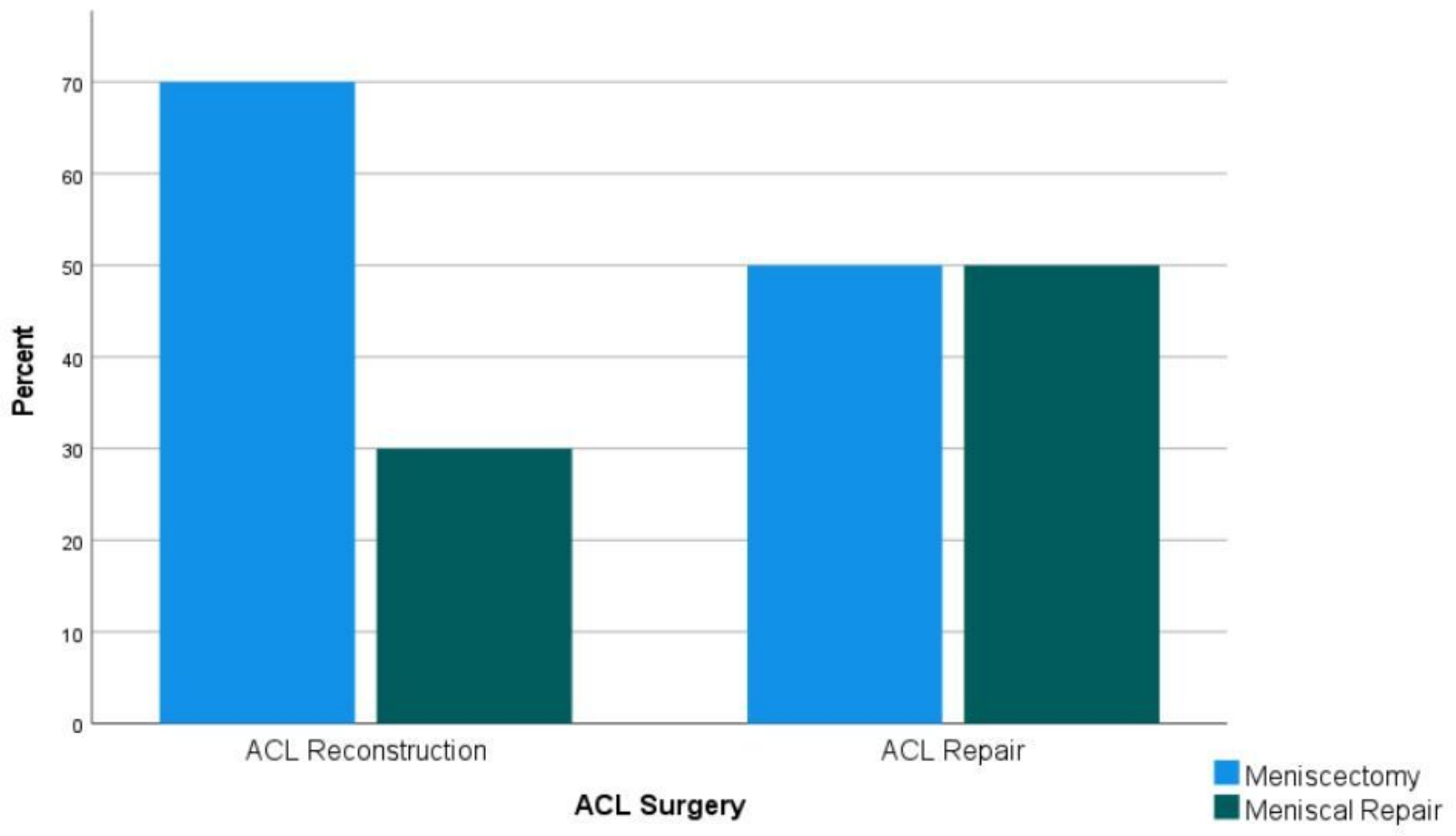

Figure 2

Graph showing type of meniscal surgery in each ACL group (\%) 

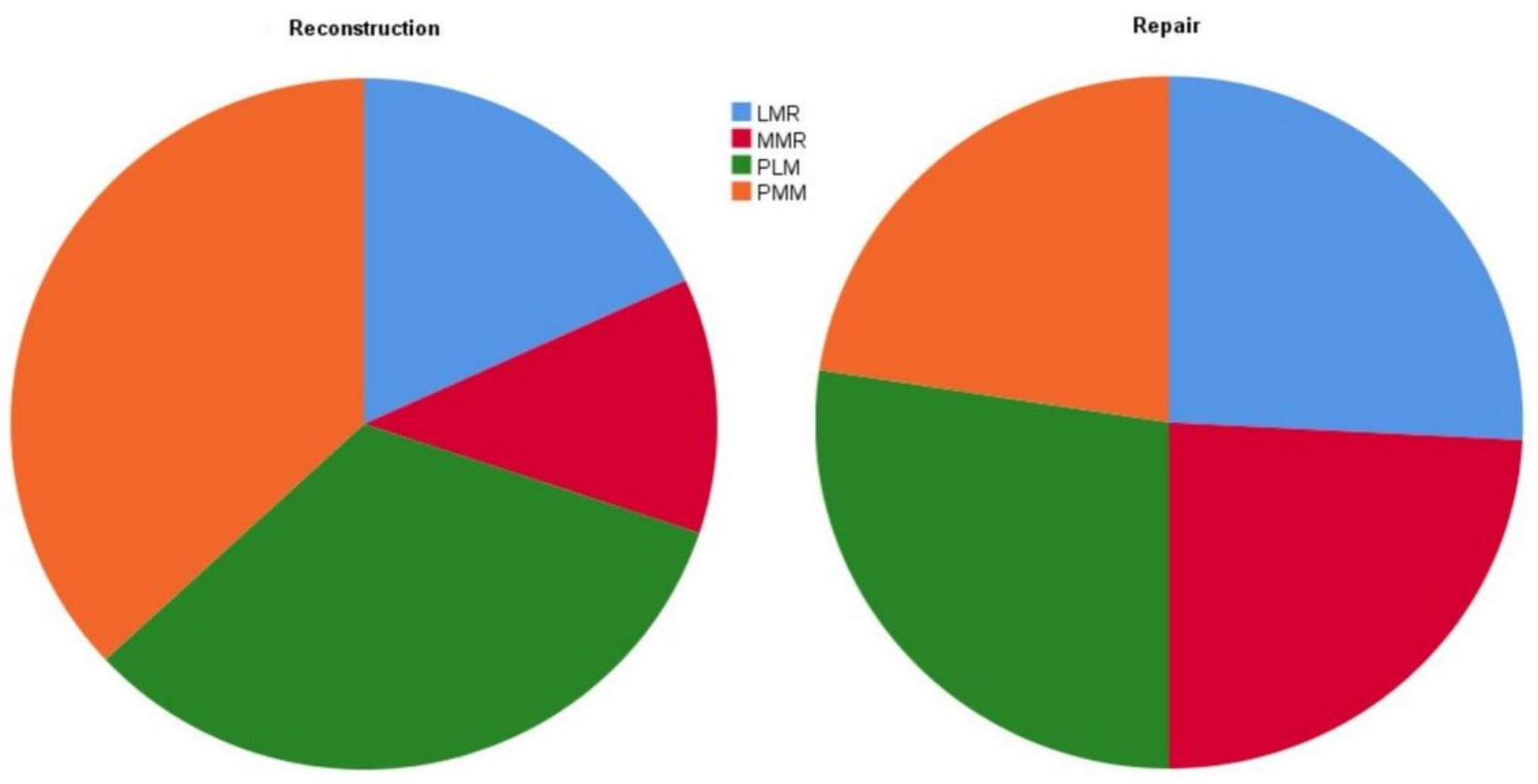

\section{Figure 3}

Chart showing proportion of meniscal surgery by type and location in each ACL treatment group (LMR= lateral meniscal repair, MMR= medial meniscal repair, PLM: partial lateral meniscectomy, PMM: partial medial meniscectomy) 


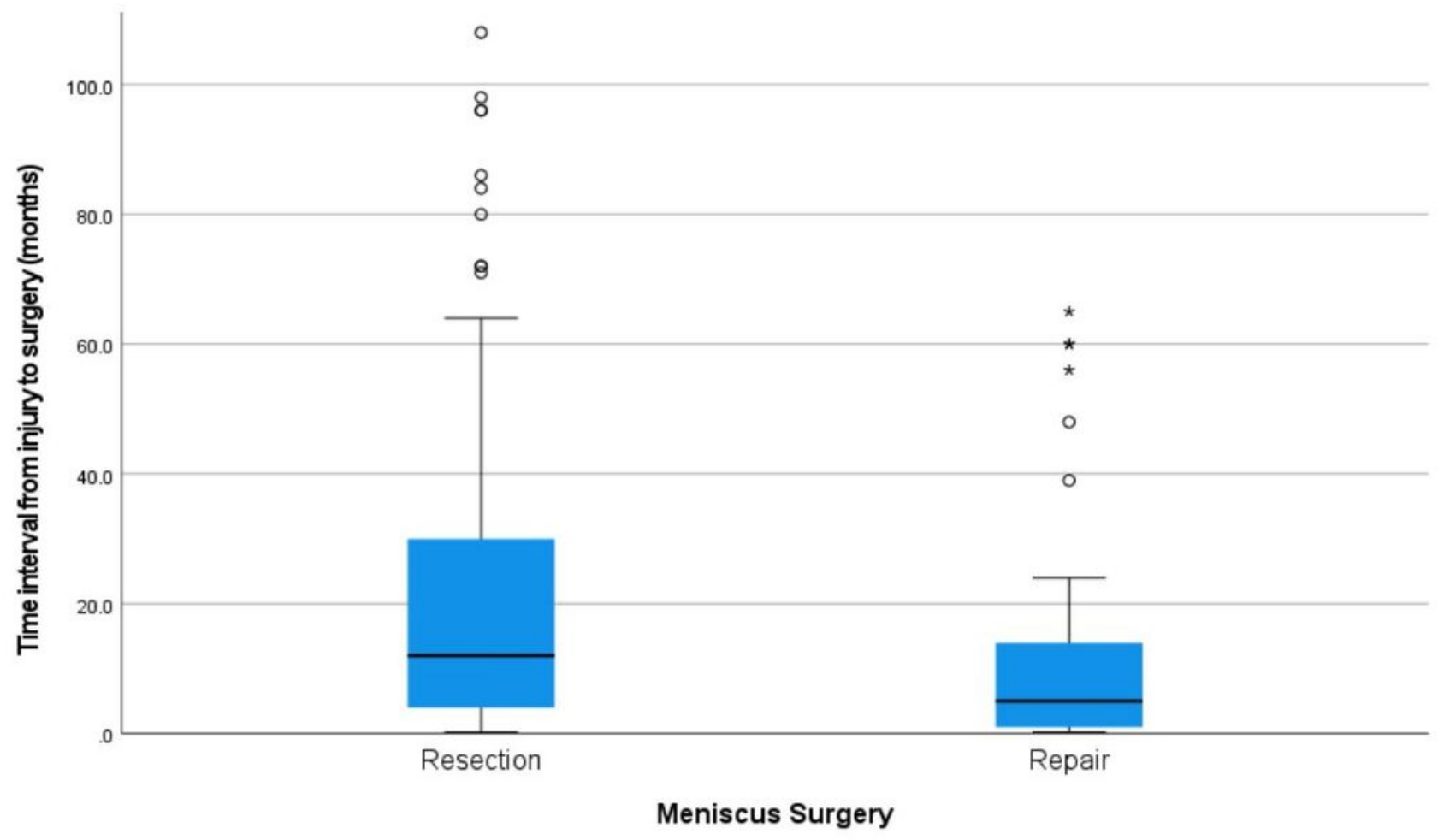

Figure 4

Boxplot demonstrating shorter time interval from injury to surgery for meniscal tears which were repairable 


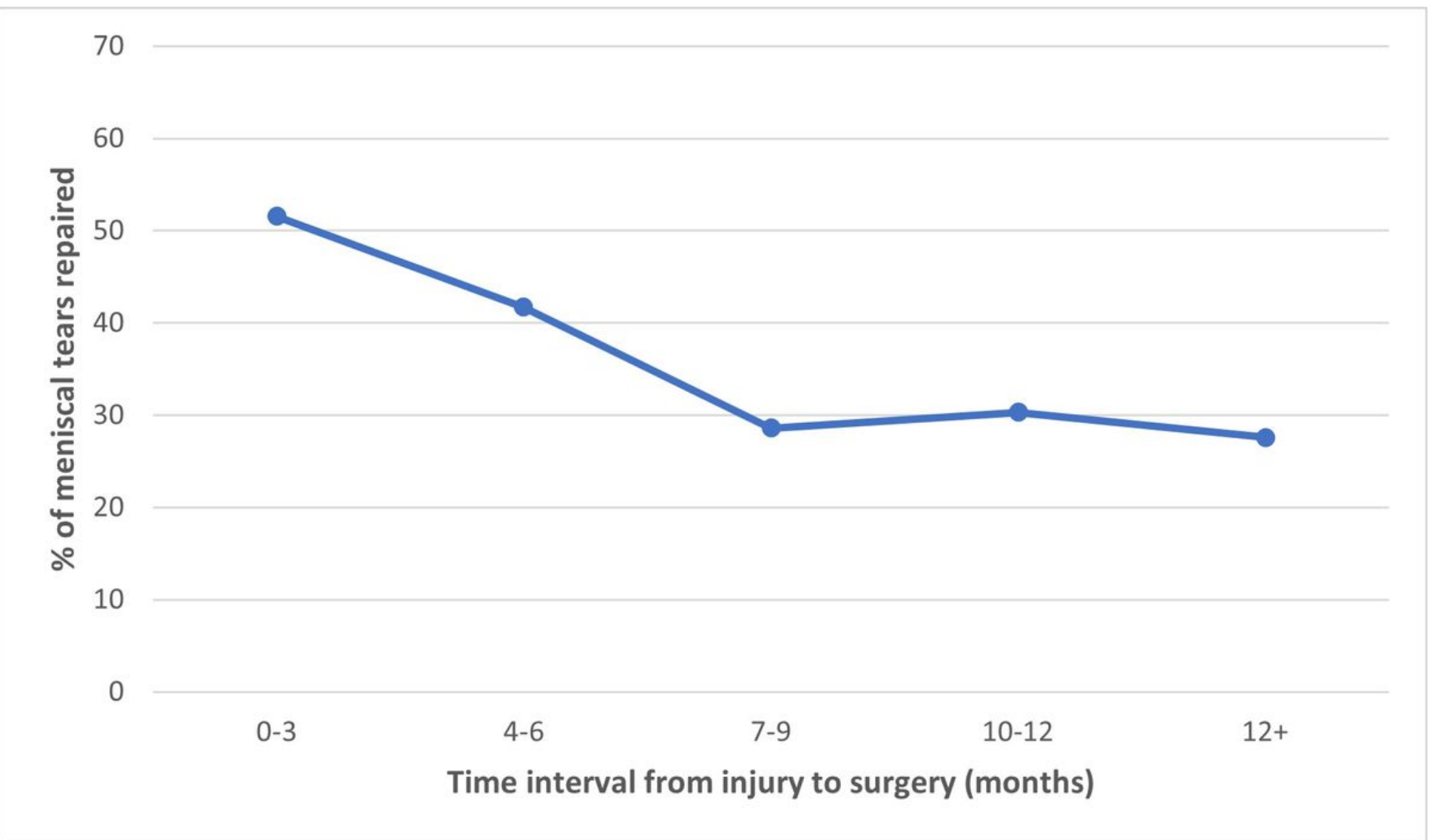

\section{Figure 5}

Graph showing the rate of repair for all meniscal tears grouped by the time interval from injury to surgery 